\title{
Path Analysis of Interrelations of Some Components Determining the Number of Florets per Shoot in Gypsophila paniculata L.
}

\author{
Takahiro Hayashi****, Hitoshi Kakeya and Kuniyoshi Konishi \\ Faculty of Agriculture, Okayama University, Tsushima-naka, Okayama 700-8503, Japan
}

\begin{abstract}
Plants of Gypsophila paniculata L. 'Bristol Fairy' were grown in boxes at nine different shoot densities to know how the number of florets per shoot, a basis of flower quality, was determined during plant growth and development. Four components were defined to analyze the number of florets per shoot (FN): number of nodes (NN), primary branches (PB), secondary branches (SB), and units (=dichasia: UN). NN, PB, SB, UN, and FN were considered to be determined in this order during plant growth and development. Fresh weight, stem diameter (SD), PB, SB, UN, and FN of cut flowers decreased as shoot density increased. Total weight of cut flowers and total number of florets per box were almost equal, except in three low-density plots. Days to visible bud and days to flowering tended to decrease as the number of shoots per plant decreased. Path analysis was used to estimate the interrelationship among components. Stem diameter was defined as an outer variable. Path coefficients of

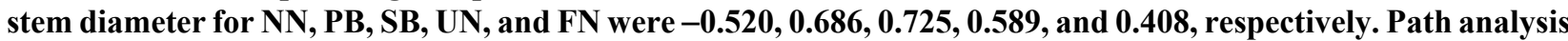
indicated that stem diameter had strong direct effects on each component. The correlation coefficient between SD and FN was 0.985 . Stem diameter has a strong indirect influence on the number of florets per shoot and can be used as an index to predict FN.
\end{abstract}

Key Words: flowering, Gypsophila paniculata L., path analysis, pipe model, yield component.

\section{Introduction}

Because Gypsophila paniculata L. is used as a filler flower in bouquets, there is greater demand for full Gypsophila paniculata L. cut flowers with a large number of florets (Fudano et al., 2002). Currently, G. paniculata L. is cultivated across Japan in both cold and warm climates and is harvested and shipped yearround. The production quantity of G. paniculata L. has reached a plateau, and competition among production areas is fiercely increasing. There is a great difference in bid prices between superior and inferior products; therefore, growers plant G. paniculata L. at a low density to produce cut flowers of high quality.

G. paniculata L. is composed of compound inflorescence and forms panicles, which have dichasia as the constitutional units (Hayashi et al., 1992). The volume of the panicle is determined by the number of branches and the number of florets per dichasium that develop on

Received; August 23, 2008. Accepted; December 12, 2008.

* Corresponding author (E-mail: thayashi@kais.kyoto-u.ac.jp).

** Present address: Graduate School of Agriculture, Kyoto University, Oiwake-cho, Kitashirakawa, Kyoto 606-8502, Japan. branch tips; however, it is unclear what factors affect these numbers during the cultivation process and therefore influence cut flower quality.

Studies on rice have identified methods to rationally increase rice production by dividing the yield into several distinct components. The yield of hulled rice per unit area was broken down into components, such as the number of ears per unit area, the number of unhulled rice grains per ear, the percentage of ripened grain, and the weight of a hulled rice grain. Factors, such as variety and the cultivation environment, were then examined for their effect on these individual components and the eventual yield (Agata, 1993). Rational approaches focusing on yield components and cultivars that are specifically oriented to improve yield contribute to the current high-yield techniques (Casanova et al., 2002; Seker and Serin, 2004).

In the present paper, we applied the same methodology used to investigate rice yield components to elucidate the process that determines the number of florets, the cut flower quality of G. paniculata L. We examined the numbers of nodes $(\mathrm{NN})$, primary branches $(\mathrm{PB})$, secondary branches (SB), and dichasia (UN) (hereafter, called "units" because a whole inflorescence is an 
aggregate of a large number of dichasia) as determinants of the number of florets, and attempted to elucidate how these components are determined along with plant growth using path analysis, which is a technique used to analyze causality.

\section{Materials and Methods}

A previous study on the regularity of inflorescence development in Gypsophila paniculata L. reported that stem diameter and the number of florets were highly correlated (Hayashi et al., 1992). To clarify the relationship between these factors, we analyzed how stem diameter affects the number of florets during the growth process.

Experiments were performed using boxes $60 \mathrm{~cm}$ long, $36 \mathrm{~cm}$ wide, and $18 \mathrm{~cm}$ deep. Shoot density per box was changed by varying the number of plants per box and shoots per plant. The effects of shoot density on stem diameter over time and the determinants of the number of florets were examined. Causal correlations in the process that determines the number of florets in G. paniculata L. were then examined based on path analysis of the relationships between stem diameter and each component.

On March 12, 1990, branches were acquired from parental plants 'Bristol Fairy', which were overwintered in an open field, and then cuttings were grown by the mist propagation method. A designated number of rooted cuttings were planted in each box for each test group on April 3, and plants were pinched to leave five nodes per plant on April 11. Nine test groups were prepared for the experiment, and the number of plants per box and shoots per plant for each group were as follows: 6 $\times 3,8 \times 2,6 \times 2,4 \times 3,3 \times 4,4 \times 2,6 \times 1,2 \times 2$, and $1 \times 2$ [(number of plants per box $) \times($ shoots per plant $)]$. In the actual cultivation of $G$. paniculata L., standard shoot density ranges between $2 \times 2$ and $1 \times 2$. Each experimental group consisted of two boxes. The boxes were arranged in north-south orientation into a length-wise double line according to the randomized blocks method. Extra boxes were placed at the south end of the experimental boxes to eliminate an edge effect. Plants were trimmed to fit predefined shoot densities on April 27.

Chemical fertilizer containing $\mathrm{N}: \mathrm{P}: \mathrm{K}$ at $13: 13: 13$ was applied at $16.6 \mathrm{~g}$ per box $\left(1 \mathrm{~kg} \mathrm{~N}\right.$ per $\left.100 \mathrm{~m}^{2}\right)$ on April 19 and May 19. Each box was irrigated as needed.

Budding and flowering dates were recorded. In addition, shoot length, NN, and stem diameter were measured every week from May 11 to June 1. Plants were harvested on the day when the primary flower (a terminal flower) died, i.e., in the standard flowering stage for a cut flower of G. paniculata L. Shoot length, fresh weight, stem diameter, NN, PB, SB, UN, and FN were evaluated for all shoots.

Data were analyzed using path analysis, which is a causality analysis technique developed by Wright (Asher, 1983) that is often used in social sciences,

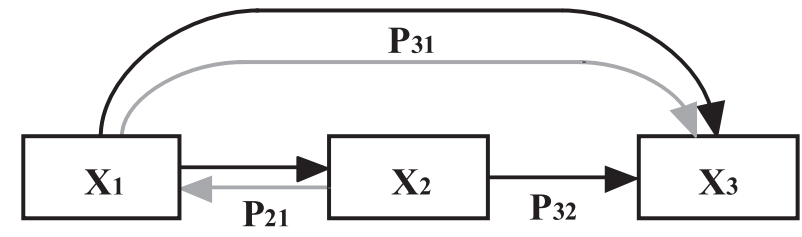

Fig. 1. Relationship between correlation coefficients and path coefficients. Correlation coefficient $=$ Direct effect + Indirect effect + False correlation coefficient. Direct effects: $\mathrm{P}_{21}, \mathrm{P}_{32}, \mathrm{P}_{31}$. Indirect effect: $\mathrm{P}_{21} \times \mathrm{P}_{32}$. False correlation coefficient: $\mathrm{P}_{21} \times \mathrm{P}_{31}$. Correlation coefficients between $\mathrm{X}_{1}$ and $\mathrm{X}_{3}: \mathrm{R}_{13}=\mathrm{P}_{31}+\mathrm{P}_{21} \times$ $P_{32}$. Correlation coefficients between $X_{2}$ and $X_{3}: R_{23}=P_{32}+P_{21}$ $\times \mathrm{P}_{31}$

heritability analyses in zootechnics, and yield analyses in horticultural science and agronomics (Duarte and Adams, 1972; Hoover et al., 1988; Karlsson et al., 1988; Nehrbas and Pritts, 1988; Robbins and Sjulin, 1989; Thurling, 1974). Path analysis compares the extent of a relative effect by breaking down the correlation strength among parameters into direct or indirect causal chains. In this study, components that determine the number of florets per shoot were arranged according to the order of correlation coefficients using path analysis, so these components could be examined for their effect on the final number of florets by examining the causal influences of each factor. $\mathrm{NN}, \mathrm{PB}, \mathrm{SB}, \mathrm{UN}$, and $\mathrm{FN}$ were determined in this order along with plant growth while being affected by cultivation environment; therefore, path coefficients were estimated with a recursive model using stem diameter as an exogenous variable and the determinants of the number of florets as an endogenous variable (Asher, 1983).

Path analysis can break down correlation coefficients into direct and indirect effects and false correlations (Asher, 1983). Figure 1 shows the relationship between correlation and path coefficients, $\mathrm{P}_{21}, \mathrm{P}_{32}$, and $\mathrm{P}_{31}$, which represent the direct effect from $X_{1}$ to $X_{2}$, from $X_{2}$ to $X_{3}$, and from $X_{1}$ to $X_{3}$, respectively. The indirect effect is an effect in which $X_{1}$ affects $X_{3}$ through $X_{2}$, and is represented as $\mathrm{P}_{21} \times \mathrm{P}_{31}$, as shown in Figure 1. A false correlation is an effect in which $\mathrm{X}_{2}$ affects $\mathrm{X}_{3}$ through a path with countering arrows, and is also represented as $\mathrm{P}_{21} \times \mathrm{P}_{31}$ using the coefficients; therefore, the correlation coefficient $R_{13}$ between $X_{1}$ and $X_{3}$ is $P_{31}+$ $\mathrm{P}_{21} \times \mathrm{P}_{32}$, and the correlation coefficient $\mathrm{R}_{23}$ between $X_{2}$ and $X_{3}$ is $P_{32}+P_{21} \times P_{31}$. A positive path coefficient represents a positive effect, a negative path coefficient represents a negative effect, and a larger absolute value indicates a stronger effect.

\section{Results and Discussion}

\section{Effect of shoot density on shoot growth}

Shoot growth was greatly affected by shoot density (Table 1). Fresh weight, stem diameter, PB, SB, UN, and FN tended to decrease as shoot density increased; however, when these components were compared according to the number of shoots per box, the total 
Table 1. Effects of shoot density on growth, development, and flowering of Gypsophila paniculata L.

\begin{tabular}{|c|c|c|c|c|c|c|c|c|c|c|c|c|}
\hline $\begin{array}{l}\text { Shoot } \\
\text { density }^{2}\end{array}$ & $\begin{array}{l}\text { Days to } \\
\text { visible bud }\end{array}$ & $\begin{array}{l}\text { Days to } \\
\text { flowering }\end{array}$ & $\begin{array}{l}\text { Shoot length } \\
(\mathrm{cm})\end{array}$ & $\begin{array}{c}\text { Fresh weight } \\
\left(\mathrm{g} \cdot \text { shoot }^{-1}\right)\end{array}$ & $\begin{array}{c}\text { Stem } \\
\text { diameter } \\
(\mathrm{mm})\end{array}$ & $\begin{array}{c}\text { Number of } \\
\text { nodes } \\
\left(\cdot \text { shoot }^{-1}\right)\end{array}$ & $\begin{array}{c}\text { Number of } \\
\text { primary } \\
\text { branches } \\
\left(\cdot \text { shoot }^{-1}\right)\end{array}$ & $\begin{array}{l}\text { Number of } \\
\text { secondary } \\
\text { branches } \\
\left(\cdot \text { shoot }^{-1}\right)\end{array}$ & $\begin{array}{l}\text { Number } \\
\text { of units } \\
\left(\cdot \text { shoot }^{-1}\right)\end{array}$ & $\begin{array}{l}\text { Number of } \\
\text { florets } \\
\left(\cdot \text { shoot }^{-1}\right)\end{array}$ & $\begin{array}{c}\text { Total } \\
\text { fresh } \\
\text { weight } \cdot \mathrm{m}^{-2}\end{array}$ & $\begin{array}{c}\text { Total number } \\
\text { of } \\
\text { florets } \cdot \mathrm{m}^{-2}\end{array}$ \\
\hline $6 \times 3$ & $53.7 \pm 0.6^{y}$ & $3.2 \pm 0.6$ & $77.3 \pm 1.3$ & $61.2 \pm 3.8$ & $5.5 \pm 0.1$ & $26.1 \pm 0.3$ & $19 \pm 0.3$ & $93 \pm 4$ & $330 \pm 22$ & $2325 \pm 215$ & 5006 & 190243 \\
\hline $8 \times 2$ & $54.1 \pm 1.0$ & $73.1 \pm 1.1$ & $73.0 \pm 3.3$ & $70.2 \pm 7.4$ & $5.5 \pm 0.2$ & $26.2 \pm 0.4$ & $18 \pm 0.7$ & $91 \pm 8$ & $331 \pm 40$ & $2545 \pm 370$ & 5106 & 185066 \\
\hline $6 \times 2$ & $52.3 \pm 0.8$ & $71.4 \pm 0.7$ & $79.6 \pm 1.5$ & $88.5 \pm 7.8$ & $6.0 \pm 0.1$ & $25.4 \pm 0.3$ & $20 \pm 0.3$ & $113 \pm 6$ & $448 \pm 35$ & $3451 \pm 412$ & 4826 & 188227 \\
\hline $4 \times 3$ & $53.6 \pm 0.6$ & $73.1 \pm 0.5$ & $81.1 \pm 1.2$ & $89.6 \pm 5.8$ & $6.1 \pm 0.1$ & $26.2 \pm 0.3$ & $19 \pm 0.4$ & $114 \pm 5$ & $468 \pm 31$ & $3441 \pm 300$ & 4889 & 187675 \\
\hline $3 \times 4$ & $55.5 \pm 0.6$ & $74.7 \pm 0.8$ & $81.3 \pm 1.4$ & $84.0 \pm 8.1$ & $5.6 \pm 0.2$ & $26.8 \pm 0.3$ & $18 \pm 0.6$ & $92 \pm 9$ & $369 \pm 43$ & $2932 \pm 378$ & 4584 & 159898 \\
\hline $4 \times 2$ & $50.8 \pm 0.5$ & $71.4 \pm 0.4$ & $85.9 \pm 1.0$ & $125.6 \pm 8.8$ & $6.6 \pm 0.2$ & $25.6 \pm 0.3$ & $21 \pm 0.5$ & $134 \pm 6$ & $586 \pm 43$ & $4972 \pm 417$ & 4567 & 180782 \\
\hline $6 \times 1$ & $50.3 \pm 0.8$ & $70.2 \pm 0.7$ & $84.8 \pm 1.8$ & $165.5 \pm 8.7$ & $6.9 \pm 1.3$ & $24.5 \pm 0.5$ & $22 \pm 0.5$ & $151 \pm 6$ & $689 \pm 45$ & $5848 \pm 434$ & 4514 & 159486 \\
\hline $2 \times 2$ & $51.1 \pm 0.7$ & $71.1 \pm 0.7$ & $87.4 \pm 1.0$ & $217.6 \pm 18.1$ & $7.8 \pm 0.2$ & $25.5 \pm 0.3$ & $21 \pm 0.4$ & $161 \pm 6$ & $873 \pm 67$ & $7671 \pm 793$ & 3956 & 139466 \\
\hline $1 \times 2$ & $53.3 \pm 0.9$ & $72.5 \pm 0.6$ & $89.4 \pm 1.7$ & $273.0 \pm 7.3$ & $8.4 \pm 0.1$ & $25.0 \pm 0.6$ & $21 \pm 0.7$ & $176 \pm 2$ & $953 \pm 25$ & $10087 \pm 336$ & 2481 & 91698 \\
\hline
\end{tabular}

Rooted cuttings were planted in boxes $(\mathrm{L} 60 \mathrm{~cm} \times \mathrm{W} 36 \mathrm{~cm} \times \mathrm{D} 18 \mathrm{~cm}$ ) on April 3. Plants were pinched on April 11 leaving 5 nodes. Flowering shoots were harvested when the terminal floret was senescent.

${ }^{z}$ Number of plants per box $(p) \times$ number of shoots per plant $(s)$.

${ }^{y}$ Means \pm SE $(n=p \times s \times 2)$.

Table 2. Correlation coefficients among the components determing the number of florets per shoot.

\begin{tabular}{lcccrrr}
\hline \hline & Stem diameter & $\begin{array}{c}\text { Number of } \\
\text { nodes }\end{array}$ & $\begin{array}{c}\text { Number of } \\
\text { primary branches }\end{array}$ & $\begin{array}{c}\text { Number of } \\
\text { secondary } \\
\text { branches }\end{array}$ & $\begin{array}{c}\text { Number of } \\
\text { units }\end{array}$ & $\begin{array}{c}\text { Number of } \\
\text { florets }\end{array}$ \\
\hline Stem diameter & - & $-0.52^{* * *}$ & $0.51^{* * *}$ & $0.89^{* * *}$ & $0.95^{* * *}$ & $0.96^{* * *}$ \\
Number of nodes & $-0.52^{* * *}$ & - & -0.02 & $-0.41^{* * *}$ & $-0.47^{* * *}$ & $-0.56^{* * *}$ \\
Number of primary branches & $0.51^{* * *}$ & -0.02 & - & $0.67 * *$ & $0.56^{* * *}$ & $0.47^{* * *}$ \\
Number of secondary branches & $0.89^{* * *}$ & $-0.41^{* * *}$ & $0.67^{* * *}$ & - & $0.93^{* * *}$ & $0.86^{* * *}$ \\
Number of units & $0.95^{* * *}$ & $-0.47^{* * *}$ & $0.56^{* * *}$ & $0.93^{* * *}$ & - & $0.96^{* * *}$ \\
Number of florets & $0.96^{* * *}$ & $-0.56^{* * *}$ & $0.47^{* * *}$ & $0.86^{* * *}$ & $0.96^{* * *}$ & - \\
\hline
\end{tabular}

*** Significant at $0.1 \%$ level by $t$-test $(\mathrm{n}=174)$.

fresh weight and total number of florets were almost equivalent among groups, except the low-density groups of $1 \times 2,2 \times 2$, and $6 \times 1$. Shinozaki and Kira (1956), who studied the effect of density in plant populations using soybeans etc., reported that growth indices, including average plant weight, were affected by planting density, while the final yield was constant and was not affected by density, which is called the law of constant final yield (Hozumi, 1977). The present study reveals that this law is also applicable to G. paniculata L. and suggests that fresh shoot weight and the number of florets are determined depending on shoot density up to a ceiling of a certain value per unit of area. Based on the area of the boxes $\left(0.22 \mathrm{~m}^{2}\right)$ used in this study, the upper limit of fresh weight and the number of florets per $1 \mathrm{~m}^{2}$ were estimated to be 4,500-5,000 $\mathrm{g}$ and $180,000-190,000$ florets, respectively. In this experiment, high-density groups of $4 \times 2$ and higher have reached the upper limit. In these cases, it is estimated that the fresh shoot weight and number of florets would be calculated as: (upper limit)/(number of shoots).

There was a tendency that the fewer the number of shoots per plant, the earlier the budding and flowering times; however, the number of shoots per plant had less effect on growth than shoot density. Cut flowers from a group of four shoots per plant $(3 \times 4$ group $)$ had fewer florets as a result of more nodes and fewer branches

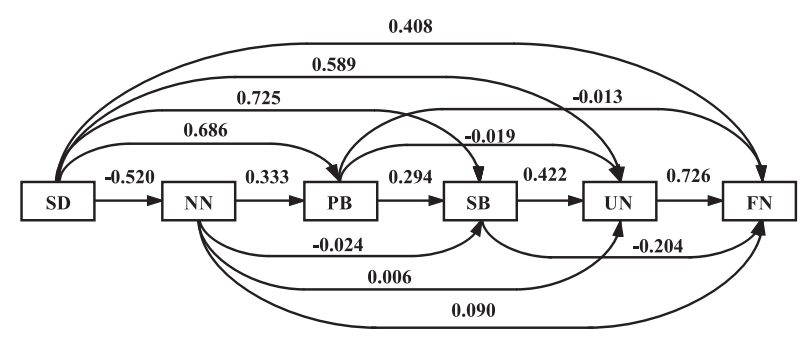

Fig. 2. Path diagram indicating the interrelationships among the components determing the total number of florets per shoot. SD: Stem diameter, NN: Number of nodes, PB: Number of primary branches, SB: Number of secondary branches, UN: Number of Units, FN: Number of florets. Numbers correspond to path coefficients.

compared to other groups with the same shoot density $(6 \times 2$ and $4 \times 3$ groups $)$. On the other hand, a group with one shoot per plant had fewer nodes and relatively larger numbers of branches and florets.

\section{Path analysis of the yield components}

The correlation coefficients for each component determining $\mathrm{FN}$ and the results of the path analysis in G. paniculata L. are summarized in Table 2 and Figure 2, respectively. The path coefficients of stem diameter for $\mathrm{NN}, \mathrm{PB}, \mathrm{SB}, \mathrm{UN}$, and FN were $-0.520,0.686,0.725$, 0.589 , and 0.408 , respectively. These data suggest that 
all factors that determine FN were strongly and directly affected by stem diameter. The correlation coefficient between the stem diameter and FN was 0.958 , indicating that the stem diameter affected FN when an indirect effect was included. Path coefficients for the stem diameter and $\mathrm{NN}$ (in this case, these are equivalent to correlation coefficients) were negative, suggesting that $\mathrm{NN}$ decreases while floral buds initiate earlier as stems become thicker. In addition, the path coefficients for FN were positive for $\mathrm{UN}$ and negative for $\mathrm{PB}$ and SB. These results indicate that $\mathrm{FN}$ is increased when $\mathrm{UN}$ is increased, while FN is decreased by excess branches because of over-luxuriant growth. Based on path analysis, controlling stem diameter is important to obtain cut flowers with a large number of florets.

\section{Temporal changes in stem diameter}

As an important morphological parameter involved in FN, temporal changes in stem diameter were determined (Fig. 3). The shoot stem diameter was affected by the number of shoots per plant during vegetative growth.

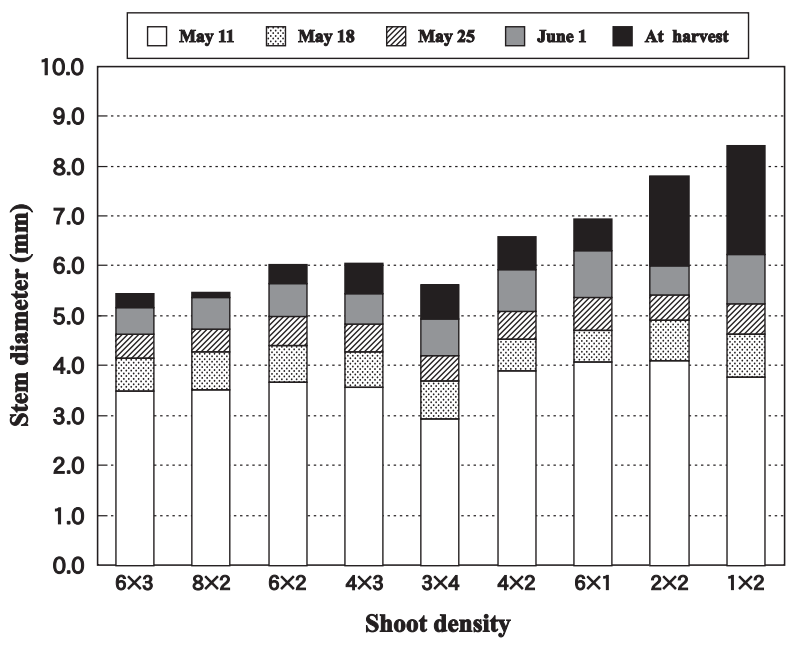

Fig. 3. Effect of shoot density on stem diameter increase. Rooted cuttings were planted in boxes (W $36 \mathrm{~cm} \times \mathrm{L} 60 \mathrm{~cm} \times \mathrm{D} 18 \mathrm{~cm}$ ) on April 3. Plants were pinched leaving 5 nodes on April 11.
The shoot length on May 11, one month after picking, was $3-5 \mathrm{~cm}$ and $\mathrm{NN}$ was $6-7$. Plants with a fewer number of shoots per plant tended to have thicker stems. After flower differentiation, however, stem diameter was gradually affected more strongly by shoot density. During budding (beginning of June) through flowering (end of June), stem diameter was remarkably increased in low-density groups. When the flowers were harvested, stem diameter was small and still strongly affected by shoot density, except in one group with four shoots per plant ( $3 \times 4$ group). These data suggest that the increased stem diameter of G. paniculata L. is strongly affected by mutual shading caused by stem and leaf overgrowth.

\section{Growth and flowering}

G. paniculata L. forms panicles, which have dichasia as units of inflorescence (units) (Hayashi et al., 1992). In the present experiment, to clarify the modality of growth and flowering in G.paniculata L., temporal changes in stem diameter at different shoot densities, FN in positions at each hierarchical level of primary and secondary branches, and units were completely examined. Cut flowers from nine test groups varied considerably; however, there were regularities between the growth/development of a stem and the axis of inflorescence and FN at the tips. Their features are summarized below (Fig. 4).

The growth and flowering of G. paniculata L. could be understood using a simple pipe model (Hayashi, 1993; Hayashi et al., 1992). In this model, it was assumed that one hypothetical unit pipe corresponds to one floret, and a stem is considered an assembly of unit pipes that are equal in number to the number of florets. It is considered that the thickness of the unit pipes is identical everywhere, and that stem thickness is proportional to the number of pipes. Thus, the base of the stem is thicker than other parts because more pipes are gathered at the base and a thick stem has many florets, which are supported physiologically and mechanically by part of the stem.
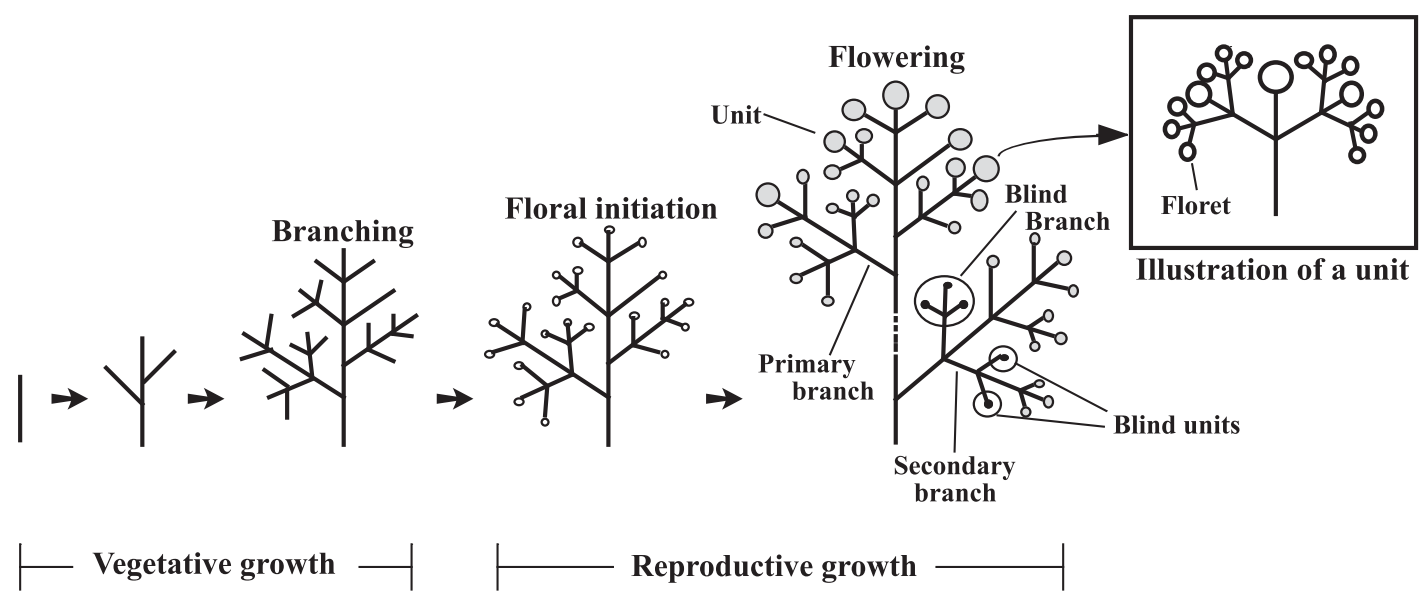

Fig. 4. Plant growth and flowering of Gypsophila paniculata L. 
The development of the main stem and branches depends on the thickness of the stem or branches. A thicker stem branches more and develops more units. Similarly, a unit with a thicker inflorescence axis develops more florets. If the branch or unit is too thin to develop units and florets, the branch or unit cannot flower.

The inflorescence of G. paniculata L. has units with thicker axes and many florets at the upper level. In middle-level nodes, the primary branches are thick and long with many units, but the size of the units is smaller than nodes at the upper level. In lower-level nodes, primary branches are thinner and less developed, and secondary and tertiary branches and units often become blind branches or units. In this way, the reason why upper nodes become larger and well-developed units is because the differentiation of units in G. paniculata $\mathrm{L}$. progresses basipetally from the top to the lower level. In addition, it is suggested that the development of units in middle- to lower-level nodes may be limited by competition for assimilation products and by mutual shading. When shoot density exceeded the upper limit, fresh weight and FN per unit of area became constant. This was thought to occur because the degree of mutual shading becomes greater when shoot density is increased, and as result, unflowering branches and units are relatively increased.

In this paper, we explained the growth and flowering of G. paniculata L. using the pipe model (Hayashi et al., 1992), and concluded that the number of florets per shoot is affected by factors that determine the number of florets through a causal chain. These results indicated that this simplified model is useful to understand a complicated process such as the development of inflorescence.

\section{Literature Cited}

Agata, W. 1993. Shuryou to hinsitsu. p. 215-234. In: K. Hoshikawa (ed.). Shokubutsuseisangakugairon (In Japanese). Buneidoshuppan, Tokyo.
Asher, H. B. 1983. Causal modeling. SAGE Publications, Newbury Park.

Casanova, D., J. Goudriaan, M. M. Catala Forner and J. C. M. Withagen. 2002. Rice yield prediction from yield components and limiting factors. Europ. J. Agronomy 17: 41-61.

Duarte, R. A. and M. W. Adams. 1972. A path coefficient analysis of some yield component relationships in field beans (Phaseolus vulgaris). Crop Sci. 12: 579-582.

Fudano, T., T. Hayashi and S. Yazawa. 2002. Plant density assuming cut flower production for the arrangement in Gypsophila paniculata L. Hort. Res. (Japan) 1: 187-190 (In Japanese with English abstract).

Hayashi, T. 1993. Kajyo no naritachi to hattatsu. p. 307-314. Nogyogijyutsutaikei Kakihen (1) (In Japanese). Nosangyosonbunkakyokai, Tokyo.

Hayashi, T., H. Miyata and K. Konishi. 1992. Inflorescence development and composition of Gypsophila paniculata L. 'Bristol Fairy'. J. Japan. Soc. Hort. Sci. 61: 135-141 (In Japanese with English abstract).

Hoover, E., J. Luby, D. Bedford and M. Pritts. 1988. Vegetative and reproductive yield components of primocane-fruiting red raspberries. J. Amer. Soc. Hort. Sci. 113: 824-826.

Hozumi, K. 1973. Shokubutsu no sougosayou. p. 8-64. Kyoritsushuppan, Tokyo.

Karlsson, M. G., M. P. Pritts and R. D. Heins. 1988. Path analysis of chrysanthemum growth and development. HortScience 23: 372-375.

Nehrbas, S. R. and M. P. Pritts. 1998. Effect of pruning system on yield components of two summer-bearing raspberry cultivars. J. Amer. Soc. Hort. Sci. 113: 314-321.

Robbins, J. and T. M. Sjulin. 1989. Fruit morphology of red raspberry and its relationship to fruit strength. HortScience 24: 776-778.

Seker, H. and Y. Serin. 2004. Explanation of the relationships between seed yield and some morphological traits in smooth bromegrass (Bromus inermis Leyss.) by path analysis. Europ. J. Agronomy 21: 1-6.

Shinozaki, K. and T. Kira. 1956. Intraspecific competition among higher plants. VII. Logistic theory of the C-D effect. J. Biol. Osaka City Univ. 7: 35-72.

Thurling, N. 1974. Morphophysiological determinants of yield in rapeseed (Brassica campestris and Brassica napus). II. Yield components. Aust. J. Agric. Res. 25: 711-721. 